\title{
Expression profiling and microRNA regulation of the LKB1 pathway in young and aged lung adenocarcinoma patients
}

\author{
LAURA BOLDRINI, MIRELLA GIORDANO, MARCO LUCCHI, FRANCA MELFI and GABRIELLA FONTANINI
}

Department of Surgical, Medical, Molecular Pathology and Critical Care Medicine, University of Pisa, I-56126 Pisa, Italy

Received March 29, 2018; Accepted June 11, 2018

DOI: $10.3892 /$ br.2018.1122

\begin{abstract}
Lung cancer in young patients appears to have distinct clinicopathological features. The present study focused on the role of the serine/threonine kinase liver kinase B1 ( $L K B 1$ ), a known tumor suppressor gene, and its miRNA regulation in lung adenocarcinoma, particularly in young versus elderly patients. A total of 88 patients with lung adenocarcinoma were retrospectively analysed. A simultaneous quantification was performed of the expression of $L K B I \mathrm{mRNA}$ and 15 microRNAs (miRNA/miRs; miRs -93, -96, -34a, -34c, -214, $-33 \mathrm{a},-30 \mathrm{~b},-145,-182,-30 \mathrm{c},-183,-29 \mathrm{~b},-29 \mathrm{c},-153$ and -138$)$ involved in the LKB1 pathway, as well as of 5 identified target mRNAs [cyclin D1 (CCND1), catenin $\beta-1$ (CTNNB1), lysyl oxidase $(L O X)$, yes-associated protein $1(Y A P 1)$ and survivin], using NanoString technology. KRAS mutations were investigated by pyrosequencing analysis. Patients $\leq 50$ years were defined as a younger group, while patients $>50$ years old as an older group ( $n=44 /$ group). No difference between the two groups was identified in terms of survival times analysed using the Kaplan-Meier method or KRAS mutations. Subsequently, the LKB1 signalling pathway was focused on, as a target for therapy in lung adenocarcinoma, and assessed with regards to clinicopathological features; we found that $L O X$ levels in adenocarcinoma patients were significantly associated with histological subtype $(\mathrm{P}=0.03)$, stage $(\mathrm{P}<0.0001)$ and prognosis $(\mathrm{P}=0.02$ for disease-free interval and $\mathrm{P}=0.005$ for overall survival), but not with age. Furthermore, the miRNA target prediction model indicated that miR-93 and miR-30b appeared to have functional binding sites and downregulate the gene expression of $L K B 1$ and $L O X$, respectively. In conclusion, young patients appeared have similar survival rates to elderly patients. The assessment of $L K B 1$, its downstream genes and its regulation by miRNAs may have an impact on future research on lung adenocarcinoma in young and elderly patients. Further
\end{abstract}

Correspondence to: Dr Laura Boldrini, Department of Surgical, Medical, Molecular Pathology and Critical Care Medicine, University of Pisa, 57 Via Roma, I-56126 Pisa, Italy

E-mail: laura.boldrini@med.unipi.it

Key words: lung adenocarcinoma, microRNA, liver kinase B1 pathway, age investigations will be necessary to elucidate the potential of this pathway as a novel target for therapy.

\section{Introduction}

Lung cancer remains the main cause of cancer-related deaths worldwide (1). Cases of non-small cell lung cancer (NSCLC) in young patients ( $\leq 50$ years old) represent a small percentage of the total cases, and indeed this disease typically affects older individuals ( $>50$ years old), and the incidence rate among elderly patients is increasing (2). Previous studies have compared young and aged NSCLC patients, using the range of 40 to 50 years to define the young group (2-8); however, to date, it is not clear if lung cancer, particularly adenocarcinoma, in young patients may have distinct clinicopathological features. In the present paper, liver kinase B1 ( $L K B 1)$ and its downstream signalling pathways were investigated as a therapeutic target in lung adenocarcinoma, a subtype of NSCLC (9), and compared between different age groups. $L K B 1$, also known as serine/threonine kinase 11 , is a tumor suppressor gene involved in cellular responses including growth, polarity and metabolism (10). LKB1 is a master kinase, controlling 14 substrates involved in the translation of several cell growth regulators (11). LKBI was been initially identified as the tumor suppressor responsible for Peutz-Jeghers syndrome, an inherited cancer predisposition (12). Several sporadic tumors exhibited $L K B 1$ promoter hypermethylation, reduced $L K B 1$ expression and somatic LKB1 mutations, indicating a role of the loss of LKB1 in cancer development and progression, potentially with additional oncogenic factors (13). LKB1 may also be repressed as a result of post-transcriptional regulation by microRNAs (miRNA/miRs) (10), which generally serve to repress mRNA translation or promote mRNA degradation via partial complementary binding to the $3^{\prime}$ untranslated region (3'-UTR) of target mRNAs (14).

The role of LKB1 in NSCLC has previously been analysed; however, study is made difficult by the fact that the LKB1 pathway involves multiple substrates that act on metabolism, apoptosis and the tumor microenvironment. Carretero et al (15) reported that NSCLC cells with loss of LKB1 exhibited higher nuclear expression of catenin $\beta-1$ (CTNNB1); LKB1, in fact, appears to suppress the Wnt/CTNNB1 pathway, inhibiting the expression of downstream genes, including cyclin D1 $(C C N D 1)$ and survivin. Additionally, lysyl oxidase (LOX) has been reported to be negatively regulated by LKB1 in 
lung cancer, and yes-associated protein 1 (YAP1) has been reported to be activated in lung adenocarcinoma as a result of a lack of LKB1 (16). In the present study, the mRNA expression of $L K B 1, C C N D 1, C T N N B 1, L O X, Y A P 1$, survivin and 15 miRNAs involved in the $L K B 1$ pathway was investigated using NanoString technology. $L K B 1$ loss has been reported to be more common within $K R A S$-mutant lung adenocarcinomas (17), and therefore, KRAS mutations were also investigated.

The results presented provide indication that $L K B 1$ pathway genes, with the involvement of miRNA regulation, may have a role in lung adenocarcinoma progression, representing novel potential targets for lung cancer therapy.

\section{Patients and methods}

Patients. A total of 88 lung adenocarcinoma patients were retrospectively selected from patients who were operated between January 2003 and December 2013 at the Unit of Thoracic Surgery of the University Hospital of Pisa (Pisa, Italy). Histological diagnoses were made according to the World Health Organization classification $(9,18,19)$. Data on clinicopathological characteristics were collected for all patients (Table I). The study was conducted in accordance with the 1964 Helsinki declaration and the ethical standards of Institutional Research Committee of the University of Pisa, for the collection of lung cancer samples following surgery and the related informed consensus for molecular analysis. Patients $\leq 50$ years old were defined as the younger group $(n=44)$, and patients $>50$ years old as the older group $(n=44)$.

Target prediction. A total of 15 miRNAs (miRs -93, -96, -34a, $-34 c,-214,-33 a,-30 b,-145,-182,-30 c,-183,-29 b,-29 c,-153$ and -138) were selected based on their involvement in the LKB1 pathway (20-29). Alignment of miRNAs with target genes ( $L K B 1, C C N D 1, C T N N B 1, L O X, Y A P 1$ and survivin) was predicted by using the microRNA target prediction program (http://www.microrna.org).

DNA and RNA isolation. DNA, RNA and miRNAs were isolated from 5-10 $\mu \mathrm{m}$ sections of formalin-fixed (buffered formalin, for 24-48 $\mathrm{h}$ at room temperature) and paraffin-embedded (FFPE) resected tissues, performed immediately following surgery, following manual tumor macrodissection using a QIAamp DNA Mini kit (Qiagen GmbH, Hilden, Germany) and a miRNeasy FFPE kit (Qiagen $\mathrm{GmbH}$ ), respectively, according to the manufacturer's instructions. The quality and concentration were assessed using a NanoDrop spectrophotometer (Thermo Fisher Scientific, Inc., Waltham, MA, USA).

NanoString $n$ Counter $^{\circledR}$ assay, data normalization and analysis. Expression of the 6 targeted mRNAs and 15 selected miRNAs was measured using the NanoString nCounter Technology system, according to the manufacturer's protocol (NanoString Technologies, Inc., Seattle, WA, USA). The nCounter measures the total counts of mRNAs/miRNAs through a multiplex hybridization assay, followed by scanning and digital readout of fluorescent probes in a high-throughput manner (30). The nCounter custom code set used in the current study included the 6 targeted genes and 3 housekeeping genes
Table I. Lung adenocarcinoma patient characteristics in the two groups.

\begin{tabular}{|c|c|c|c|c|}
\hline Variable & Young & Old & Total & $\mathrm{P}$-value \\
\hline Sample size & 44 & 44 & 88 & - \\
\hline Age, years & $46.3 \pm 3.9$ & $71.5 \pm 5.2$ & $58.9 \pm 13.4$ & - \\
\hline Sex & 0.02 & & & \\
\hline Male & 23 & 33 & 56 & \\
\hline Female & 21 & 11 & 32 & \\
\hline $\begin{array}{l}\text { Adenocarcinoma } \\
\text { prevalent pattern }\end{array}$ & & & & 0.0004 \\
\hline Lepidic & 13 & 16 & 29 & \\
\hline Solid & 9 & 17 & 26 & \\
\hline Acinar & 19 & 3 & 22 & \\
\hline Papillar & 3 & 8 & 11 & \\
\hline Tumour grading & & & & 0.07 \\
\hline G1 & 3 & 0 & 3 & \\
\hline $\mathrm{G} 2$ & 30 & 28 & 58 & \\
\hline G3 & 11 & 16 & 27 & \\
\hline Stage & & & & 0.79 \\
\hline IA & 8 & 9 & 17 & \\
\hline IB & 14 & 9 & 23 & \\
\hline IIA & 6 & 7 & 13 & \\
\hline IIB & 4 & 5 & 9 & \\
\hline IIIA & 10 & 13 & 23 & \\
\hline IIIB & 1 & 0 & 1 & \\
\hline IV & 1 & 1 & 2 & \\
\hline KRAS status & & & & 0.07 \\
\hline Wild-type & 31 & 23 & 54 & \\
\hline Mutant & 13 & 21 & 34 & \\
\hline
\end{tabular}

Age is provided as the mean \pm standard deviation; all other values represent case number.

as references (tubulin $\beta$, hypoxanthine phosphoribosyltransferase and phosphoglycerate kinase 1). Raw NanoString counts for each gene were subjected to technical and biological normalization using the positive control probe sets and three reference genes, respectively. miRNAs were normalized using a scaling factor based on the 5 miRNAs with the lowest variability coefficients according to the manufacturer's protocol.

KRAS mutation analysis. Pyrosequencing analysis was performed using the PyroMark Q96 ID platform (Diatech Pharmacogenetics SRL, Jesi, Italy) following the manufacturer's instructions in order to determine KRAS status. Codons 12, 13, 61, 117 and 146 of the KRAS gene were analysed.

Statistical analysis. The normalized RNA hybridization data, presented as direct counts of digital reports, were analysed by using nSolver 2.5 analysis software (NanoString Technologies, Inc.). The $\chi^{2}$ test was applied to analyze lung adenocarcinoma patient characteristics in the two age groups and to determine the association between $L K B 1$ and miR-93 expression. 

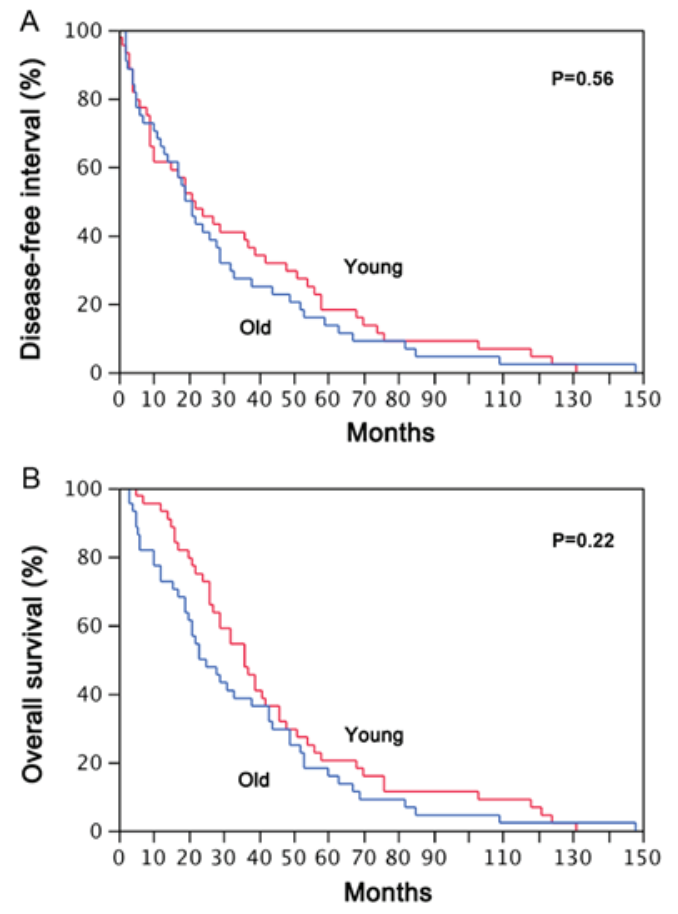

Figure 1. Kaplan-Meier curves for the analysis of (A) disease-free interval and (B) overall survival in younger and older lung adenocarcinoma patients ( $n=44$ /group).

Differential gene expression was determined by applying the non-parametric $t$ test and analysis of variance. Survival analyses were performed using the Kaplan-Meier method with the log-rank test and the Cox proportional hazard model. Statistical analyses were performed using JMP 10 software (SAS Institute, Inc., Cary, NC, USA), and two-tailed $\mathrm{P}<0.05$ was considered to indicate statistical significance.

\section{Results}

Comparison of patient characteristics between the age groups. The current study was conducted in 88 patients with lung adenocarcinoma (56 males and 32 females). Patients $\leq 50$ years old were defined as the younger group, and patients $>50$ years old as the older group. Among all patients, different histological subtypes of adenocarcinoma were identified; the most common histological subtypes were lepidic (29/88, 33.0\%), solid (26/88, 29.5\%), acinar (22/88, 25.0\%), and papillar (11/88, $12.5 \%$ ). The median age at diagnosis was 54.5 years old (range, 30-81 years; mean, 58.9 \pm 13.4 years). Regarding grading, 3 tumors (3.4\%) were G1, whereas $58(65.9 \%)$ and $27(30.7 \%)$ were $\mathrm{G} 2$ and $\mathrm{G} 3$, respectively. The adenocarcinomas were all invasive, and stages 17 IA, 23 IB, 13 IIA, 9 IIB, 23 IIIA, 1 IIIB, and 2 IV were identified, according to the World Health Organization classification $(9,18,19)$. The follow-up data, disease-free interval (DFI) and overall survival (OS) were available for all patients and were last updated on March 2015. Disease progression (recurrence/metastasis) was observed in 50 patients $(56.8 \%$; data not shown). Regarding smoking habits, there were 17 non-smokers, 16 former smokers and 23 current smokers; for 33 patients, the smoking data were not available. Regarding clinicopathological characteristics, overall gender distribution $(\mathrm{P}=0.02)$ as well as histological subtype distribution $(\mathrm{P}=0.0004)$ were significantly different between the younger and older cases (Table I).

Comparison of survival between the age groups. The median DFI and OS times of total patients $(n=88)$ were 21 months (range, 0-148) and 31.5 months (range, 3-148), respectively.

The median DFI times were 22 months in younger patients and 21 months in older patients; the median OS times were 36 and 23 months in the younger and older groups, respectively. Survival analysis using the Kaplan-Meier method with DFI and OS as endpoints did not identify a significant difference between younger patients and their elderly counterparts (Fig. 1).

LKB1 pathway expression. To investigate the role of the LKB1 pathway in lung adenocarcinoma, first the levels of LKB1 were screened. As presented in Table II, there was no significant association of $L K B 1$ expression with patient age, prevalent adenocarcinoma pattern or tumor grading; however, the data indicated a significant association of low $L K B 1$ expression with male gender $(\mathrm{P}=0.03)$ and overall clinical stage $(\mathrm{P}=0.01)$ as well as a trend with the solid variant. Next it was investigated whether the expression of downstream genes and their regulation was directly affected by $L K B 1$ levels. Low $L K B 1$ expression was associated with low expression of $C C N D 1$ $(\mathrm{P}<0.0001)$, CTNNB1 $(\mathrm{P}<0.0001)$ and YAPl $(\mathrm{P}=0.0024$; data not shown), suggesting regulation by $L K B 1$. To test if $L O X$, one of the other $L K B 1$ network partners, was an important downstream mediator of lung adenocarcinoma progression, its expression level was also assessed in the present adenocarcinoma series. Notably, LOX levels in adenocarcinoma patients were significantly associated with histological subtype $(\mathrm{P}=0.03)$, as well as with stage $(\mathrm{P}<0.0001$; Table III) distribution, indicating that $L O X$ activation may promote tumor progression. The samples were divided into high and low LOX expression groups based on the median $L O X$ fold-change value (median fold-change, 132; mean, 141.82 \pm 88.9 ). Survival analysis was performed using the Kaplan-Meier method with the post-operative DFI and OS times as endpoints in order to evaluate the association between $L O X$ expression and prognosis in the adenocarcinoma patients. It was identified that adenocarcinoma cases with high $L O X$ mRNA expression were associated with significantly shorter median DFI and OS times compared with the cases with low LOX expression $(\mathrm{P}=0.02$ and $\mathrm{P}=0.005$, respectively; Fig. 2).

Taken together, these data support $L K B 1$ signalling as a key pathway in lung adenocarcinoma, with a potential relevant role for $L O X$.

miRNA selection and expression. The microRNA target prediction program (http://www.microrna.org) was used to identify putative miRNA-mRNA interactions in the LKB1 pathway, and subsequently, the impact of the 15 selected miRNAs (miRs -93, -96, -34a, -34c, -214, -33a, -30b, -145, -182, $-30 c,-183,-29 b,-29 c,-153$ and -138$)$ on the expression of target genes. Fig. 3 depicts the expression profiles across all the adenocarcinoma samples in the two age groups. The younger and older patients shared similar gene expression profiles; any differentially expressed genes in the $L K B 1$ pathway were associated with modulated miRNA expression, suggesting 
Table II. LKB1 expression in the 88 lung adenocarcinoma patients.

\begin{tabular}{lcc}
\hline Variable & $\begin{array}{c}\text { LKB1 expression, } \\
\text { mean } \pm \text { SD }\end{array}$ & P-value \\
\hline Age group & & 0.21 \\
Younger ( 550 years) & $173.9 \pm 13.4$ & \\
Older (>50 years) & $149.8 \pm 13.4$ & \\
Sex & & 0.03 \\
Male & $146.9 \pm 11.6$ & \\
Female & $188.0 \pm 15.4$ & \\
Prevalent & & \\
adenocarcinoma pattern & & \\
Lepidic & $184.9 \pm 16.4$ & \\
Solid & $137.9 \pm 17.3$ & \\
Acinar & $154.0 \pm 18.8$ & \\
Papillar & $173.1 \pm 26.7$ & \\
Tumour grading & & \\
G1 & $244.8 \pm 50.9$ & \\
G2 & $166.1 \pm 11.5$ & \\
G3 & $143.4 \pm 16.9$ & \\
Stage & & \\
I & $192.2 \pm 13.5$ & \\
II & $129.8 \pm 18.2$ & \\
III-IV & $142.3 \pm 16.7$ & \\
\hline
\end{tabular}

LKB1, liver kinase B1; SD, standard deviation.

that they were the gene targets of the modulated miRNAs. The seed region of miR-93 was predicted to bind to one site, position 287, in the human LKB1 3'-UTR (Fig. 4). The samples were divided into high and low miR-93 expression groups based on the median miR-93 fold-change value (median fold-change, 3.933; mean, 4.845.91 \pm 3.056 ); $L K B 1$ expression was reduced in samples with high miR-93 expression $\left(\chi^{2}\right.$ test; $\mathrm{P}=0.0007$; data not shown), indicating that this endogenous miRNA may suppress $L K B 1$. No statistically significant association was identified between $C C N D 1$ and miR-93 expression, even though decreased $C C N D 1$ levels tended to be observed in cases with high miR-93 expression $(\mathrm{P}=0.11)$ and an alignment at position 1013 of the 3'-UTR was identified (Fig. 4). LOX downregulation was observed in the lung adenocarcinoma specimens with high miR-30b expression $(\mathrm{P}=0.04)$, and a direct interaction of this miRNA and the 3'-UTR of the LOX gene at position 594 was identified (Fig. 4). Other potential miRNA binding sites within the LOX 3'-UTR were identified (for miRs -145, -182, -30c, -183, -29b, -29c and -153); potential miRNA binding sites were also identified in YAPl (miR-138) and survivin (miR-214-3p), but neither of them were indicated to influence the expression levels of their mRNA targets (data not shown).

KRAS mutation analysis. Pyrosequencing analysis was performed to identify mutational hot-spots of the KRAS gene. Among the 88 tumor specimens, 34 tumors (38\%) were
Table III. LOX expression in the 88 lung adenocarcinoma patients.

\begin{tabular}{lcc}
\hline Variable & $\begin{array}{c}\text { LOX expression, } \\
\text { mean } \pm \text { SD }\end{array}$ & P-value \\
\hline Age group & & 0.7 \\
Younger ( $\leq 50$ years) & $137.6 \pm 13.4$ & \\
Older (>50 years) & $146.1 \pm 13.4$ & \\
Sex & 0.05 & \\
Male & $156.1 \pm 11.6$ & \\
Female & $116.9 \pm 15.4$ &
\end{tabular}

Prevalent

0.03

adenocarcinoma pattern

$\begin{array}{lc}\text { Lepidic } & 131.0 \pm 16.0 \\ \text { Solid } & 162.9 \pm 17.0 \\ \text { Acinar } & 159.6 \pm 18.4 \\ \text { Papillar } & 85.0 \pm 26.1\end{array}$

Tumour grading

0.52

G1

G2

G3

$147.5 \pm 51.5$

$134.0 \pm 11.7$

$157.9 \pm 17.1$

$\begin{array}{ll}\text { Stage } & \\ \text { I } & 102.9 \pm 11.9 \\ \text { II } & 126.4 \pm 16.1 \\ \text { III-IV } & 214.8 \pm 14.8\end{array}$

LOX, lysyl oxidase; SD, standard deviation.
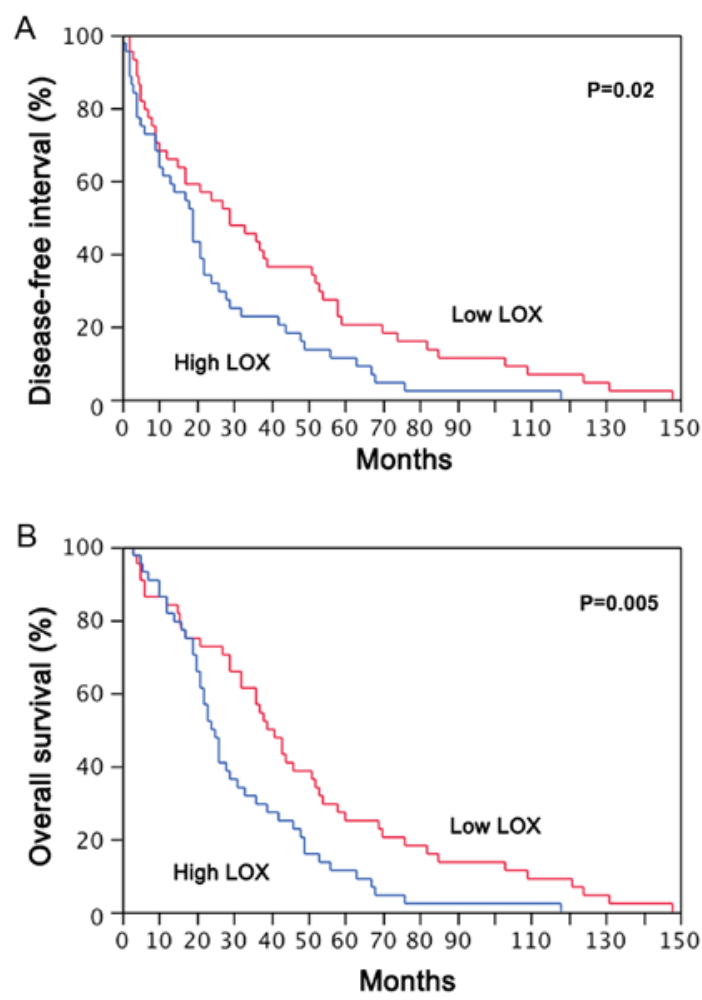

Figure 2. Kaplan-Meier curves for the survival analysis of (A) disease-free interval and (B) overall survival in the 88 adenocarcinoma patients according to $L O X$ expression level. LOX, lysyl oxidase. 


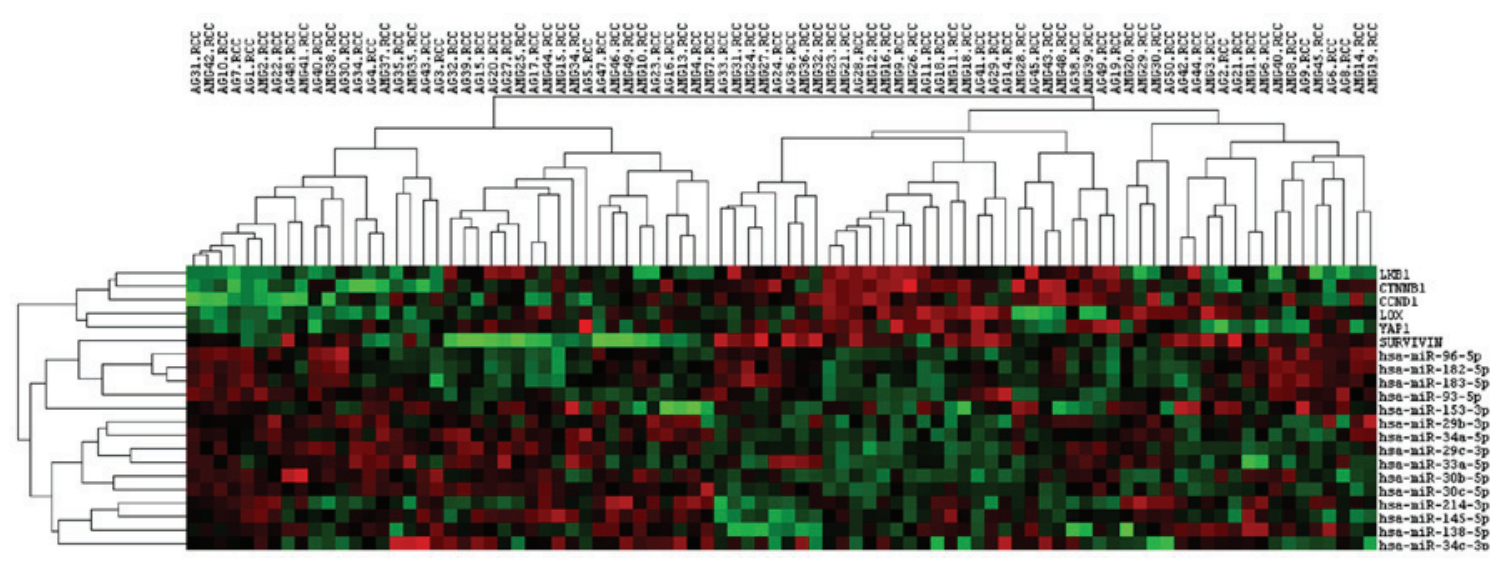

Figure 3. Comparison of gene expression profiles of younger and older lung adenocarcinoma patients. A heat map is presented of unsupervised hierarchical clustering of 6 genes and 15 miRNAs from the Nanostring gene panel based on samples from young (AG) and old (AMG) lung adenocarcinoma patients. Green indicates relatively underexpressed genes; and red indicates relatively overexpressed genes. The genes and miRNAs tested did not separate younger and older patients. miRNA/miR, microRNA; hsa, homo sapiens; LKB1, LKB1, liver kinase B1; CTNNB1, catenin $\beta-1$; CCND1, cyclin D1; LOX, lysyl oxidase; YAP1, yes-associated protein 1.

A 3' gauggacgugcuugU-CGUGAAAc $5^{\prime}$ hsa-miR-93 mirSVR score: -0.3947 $\begin{array}{lll}271: 5^{\prime} \text { gggaggcggccucCAUGCACUUUa } & 3^{\prime} \text { LKB1 } & \text { mirSVR score: }-0.3947 \\ \text { PhastCons score: } 0.5215\end{array}$

B 3' gaUgG--ACGUGCUUG-UCGUGAAAC 5' hsa-miR-93 mirSVR score: $\quad-0.3250$

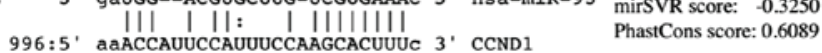

C $3^{\prime}$ ucgacucacaUCCUACAAAUGu $5^{\circ}$ hsa-miR-30b 581:5' cuauauaaaagUAUGUUUACa $3^{\circ}$ LOX

mirSVR score: -1.2730 PhastCons score: 0.6555

Figure 4. MicroRNA alignment with (A) LKB1, (B) CCND1 and (C) $L O X$ mRNA by the target prediction program (http://www.microrna.org). SVR indicates the miRNA-target prediction algorithm based on a supervised vector regression (SVR) model. miR, microRNA; hsa, homo sapiens; LKB1, liver kinase B1; CCND1, cyclin D1; LOX, lysyl oxidase.

determined to have point mutations, 13/44 among younger and 21/44 among older patients. However, no significant difference was identified in KRAS mutation distribution between the two age groups $(\mathrm{P}=0.07$; Table $\mathrm{I})$. Concerning the KRAS mutation type, the G12C substitution was present in 15 samples ( 7 younger and 8 older patients); the G12V point mutation in 11 samples (3 younger and 8 older patients); the G12D mutation in 3 samples (1 younger and 2 older patients); the G12A mutation in 2 samples from the older cohort; the G12S and G13D in 1 sample each among younger patients, and Q61L mutations in only 1 older patient (Table IV).

\section{Discussion}

Lung cancer remains the main cause of cancer-related mortality worldwide, and the age at diagnosis has been decreasing in recent years $(2,4)$. Younger patients with lung cancer appear to exhibit distinct clinicopathological features: They are more commonly non-smokers and female, and present a prevalence for adenocarcinoma and advanced disease; however, there is controversy regarding the outcome as it has been reported as improved by certain studies $(4,31)$ and unaffected by others (31-34). Data on the management of adenocarcinoma in the elderly are insufficient (35-39), and thus, whether young lung cancer patients have specific molecular and pathologic features or different survival outcomes remain unclear. In the present study, 44 lung adenocarcinoma patients $\leq 50$ years old were selected as the younger group and 44 cases $>50$ years as the older group; a predominance of females was identified in the younger group, and the acinar pattern was most prevalent, which was in accordance with previous studies $(4,40-42)$. There were no significant differences in survival, in terms of DFI and $\mathrm{OS}$, in young lung adenocarcinoma patients compared with the older age group. At present, there is no general consensus on the influence of age on survival, and this issue is open to question. Any discrepancies between reports may be due to the limited number of studies and to the specific cut-off age used to separate younger from older patients; the current study used 50 years old as the cut-off value, according to several previous reports $(2,43,44)$.

An aim of this retrospective study was also to focus on the expression pattern of $L K B 1$ and its downstream signalling pathways, in order to evaluate their associations with clinicopathological features and prognoses in lung adenocarcinoma, comparing younger patients with their elderly counterparts.

Although there are currently no drugs in routine clinical use that specifically target LKB1, there is a growing number of approaches that may differentially benefit patients with a dysregulated LKB1 pathway (45-49). A critical role for LKB1 has been suggested in catenin-betal signalling in lung cancer through its modulation of CCNDI and survivin gene expression (50). Additionally, $L O X$ has been reported to be efficiently suppressed by $L K B 1$, and $Y A P 1$ has been reported to be initially activated by $L K B 1$ loss in lung ADC.

A mRNA panel was customized of the 6 abovementioned genes and 15 miRNAs involved in the LKB1 pathway, and expression profiling was performed with NanoString technology, a recently developed platform that can make direct multiplexed measurements of expression through digital readouts of the abundance of mRNA/miRNA transcripts (51). Several studies have indicated that the NanoString technique is a reliable and flexible method for the assessment of gene expression in limited FFPE tissues, and it has exhibited similar results using fresh-frozen tissue (52-54). This field appears to be of importance, since FFPE represents most of the specimens 
Table IV. KRAS mutation distribution in the two age groups of lung adenocarcinoma patients.

\begin{tabular}{lccc}
\hline & \multicolumn{3}{c}{ Cases, $\mathrm{n}$} \\
\cline { 2 - 4 } KRAS status & $\begin{array}{c}\text { Younger } \\
(\mathrm{n}=44)\end{array}$ & $\begin{array}{c}\text { Older } \\
(\mathrm{n}=44)\end{array}$ & $\begin{array}{c}\text { Total } \\
(\mathrm{n}=88)\end{array}$ \\
\hline Wild-type & 31 & 23 & 54 \\
Mutated & 13 & 21 & 34 \\
G12C & 7 & 8 & 15 \\
G12V & 3 & 8 & 11 \\
G12D & 1 & 2 & 3 \\
G12A & 0 & 2 & 2 \\
G12S & 1 & 0 & 1 \\
G13D & 1 & 0 & 1 \\
Q61L & 0 & 1 & 1 \\
\hline
\end{tabular}

collected in routine diagnostic pathology, and it will allow for the connection of clinical follow-up data to large numbers of patients (55); therefore, the NanoString methodology may be readily adapted clinically as a highly reproducible alternative to quantitative polymerase chain reaction and sequencing methods (56).

$L K B 1$ has different molecular targets, and thus, screening of the $L K B 1$ signalling pathway appears a necessary step to explain its suppressive function in cancer cell biology. No differences in $L K B I$ levels and $K R A S$ mutation rates were identified between young and older patients, possibly due to the biological heterogeneity of KRAS-mutant lung adenocarcinomas, to the relatively small group size, and/or to other underlying molecular differences such as epidermal growth factor mutations or anaplastic lymphoma kinase translocations (18). Notably, low LKB1 expression was apparent in the solid histological subtype, and high expression in females and early clinical stage, which suggest an important role for LKB1 in inhibiting the growth of lung cancer cells, considering that the solid subtype, male gender and advanced stages are reportedly survival disadvantages in lung adenocarcinoma (57). However, it remains unclear how $L K B 1$ loss contributes to lung carcinogenesis, and the post-transcriptional regulation of $L K B 1$ may play a central role. The current results also predicted that miR-93 may be able to downregulate $L K B I$ and $C C N D 1$, consequently leading to the loss of $L K B 1$-dependent tumor suppression; such is in agreement with previous studies reporting that high levels of miR-93 (58) and low levels of $L K B 1$ (59) as well as CCND1 (60) were correlated with poor survival among lung cancer patients.

The current study also attempted to elucidate the involvement of $L O X$. It is reported that the tumor microenvironment serves a critical role in tumorigenesis (61), and that $L O X$, due to its influence on the cellular microenvironment, may be a target for cancer therapy $(62,63)$. The current data further indicated that aberrant $L O X$ expression was involved in lung carcinogenesis and cancer progression, revealing that $L O X$ levels in adenocarcinoma patients were significantly associated with overall stage distribution and poor prognosis regardless of age at diagnosis. Furthermore, the findings indicated that the observed positive prognostic effect of $L O X$ was associated, at least in part, to $\mathrm{miR}-30 \mathrm{~b}$ regulation, confirming the conclusions by Zhong et al (64) regarding a central role of this miRNA in NSCLC suppression. However, the impact of $L O X$ remains incompletely clear; it is possible that there exists multiple forms of $L O X$ proteins (65), and it is not known whether the signalling components downstream of $L K B 1$, including $L O X$, may be involved in an $L K B 1$-independent manner; further studies will be required to reach a conclusive point.

The finding that $L K B 1$ and $L O X$ may be repressed by specific miRNAs establishes a regulatory link within the LKB1 tumor suppressor pathway; miRNA-dependent post-transcriptional regulation of $L K B 1$ may be an alternative to inactivating $L K B 1$ mutations, which are rare among sporadic tumors (10). Additional study on $L K B 1$ pathways and other components of the $L K B 1$ complex may expand knowledge regarding tumor metabolism and growth potential in lung adenocarcinoma.

\section{Acknowledgements}

Preliminary results of the present study were presented as a poster at the International Association for the Study of Lung Cancer 17th World Conference on Lung Cancer, December 4-7, 2012 in Vienna, Austria and published as abstract no. P1.02-078 in Journal of Thoracic Oncology 12 (Suppl 1): 2017.

\section{Funding}

Not applicable.

\section{Availability of data and materials}

The datasets used and/or analysed during the current study are available from the corresponding author on reasonable request.

\section{Authors' contributions}

LB, MG and GF conceived and designed the experiments. MG performed the experiments. LB wrote the manuscript. GF was responsible for lung cancer diagnosis and contributed to conception and design of the study. FM and ML performed lung surgery and follow-up and contributed to conception and design of the study.

\section{Ethics approval and consent to participate}

The current study was conducted in accordance with the ethical standards of Institutional Research Committee of the University of Pisa (Pisa, Italy) and with the 1964 Helsinki declaration; informed consent for the tissue collection and molecular analysis was collected by the oncologist upon each patient's first visit from January 2003 to December 2013 to the University Hospital of Pisa (Pisa, Italy).

\section{Patient consent for publication}

Informed consent collected from all patients permitted the use of their tissues for research purposes. 


\section{Competing interests}

The authors declare that they have no competing interests.

\section{References}

1. Torre LA, Bray F, Siegel RL, Ferlay J, Lortet-Tieulent J and Jemal A: Global cancer statistics, 2012. CA Cancer J Clin 65 87-108, 2015.

2. Ramalingam S, Pawlish K, Gadgeel S, Demers R and Kalemkerian GP: Lung cancer in young patients: Analysis of a Surveillance, Epidemiology, and End Results database. J Clin Oncol 16: 651-657, 1998

3. Mauri D, Pentheroudakis G, Bafaloukos D, Pectasides D, Samantas E, Efstathiou E, Kalofonos HP, Syrigos K, Klouvas G, Papakostas P, et al; Hellenic Coopeprative Oncologic Group (HeCOG): Non-small cell lung cancer in the young: A retrospective analysis of diagnosis, management and outcome data. Anticancer Res 26 (4B): 3175-3181, 2006.

4. Subramanian J, Morgensztern D, Goodgame B, Baggstrom MQ, Gao F, Piccirillo J and Govindan R: Distinctive characteristics of non-small cell lung cancer (NSCLC) in the young: A surveillance, epidemiology, and end results (SEER) analysis. J Thorac Oncol 5: 23-28, 2010

5. Zhang J, Chen SF, Zhen Y, Xiang J, Wu C, Bao P, Luketich J, $\mathrm{Hu} \mathrm{H}$, Zhou X, Zhang J, et al: Multicenter analysis of lung cancer patients younger than 45 years in Shanghai. Cancer 116: 3656-3662, 2010

6. Inoue M, Okumura M, Sawabata N, Miyaoka E, Asamura H, Yoshino I, Tada H, Fujii Y, Nakanishi Y, Eguchi K, et al: Clinicopathological characteristics and surgical results of lung cancer patients aged up to 50 years: The Japanese Lung Cancer Registry Study 2004. Lung Cancer 83: 246-251, 2014.

7. Lara MS, Brunson A, Wun T, Tomlinson B, Qi L, Cress R, Gandara DR and Kelly K: Predictors of survival for younger patients less than 50 years of age with non-small cell lung cancer (NSCLC): A California Cancer Registry analysis. Lung Cancer 85: 264-269, 2014

8. Rich AL, Khakwani A, Free CM, Tata LJ, Stanley RA Peake MD, Hubbard RB and Baldwin DR: Non-small cell lung cancer in young adults: Presentation and survival in the English National Lung Cancer Audit. QJM 108: 891-897, 2015.

9. Travis WD, Brambilla E, Muller-Hemerlink HK and Harris CC: World Health Organization Classification of Tumours. Pathology and Genetics of Tumours of the Lung, Pleura, Thymus and Heart. IARC press, Lyon, 2004.

10. Korsse SE, Peppelenbosch MP and van Veelen W: Targeting LKB1 signaling in cancer. Biochim Biophys Acta 1835: 194-210, 2013.

11. Beroukhim R, Mermel CH, Porter D, Wei G, Raychaudhuri S, Donovan J, Barretina J, Boehm JS, Dobson J, Urashima M, et al: The landscape of somatic copy-number alteration across human cancers. Nature 463: 899-905, 2010.

12. Hemminki A, Markie D, Tomlinson I, Avizienyte E, Roth S, Loukola A, Bignell G, Warren W, Aminoff M, Höglund P, et al: A serine/threonine kinase gene defective in Peutz-Jeghers syndrome. Nature 391: 184-187, 1998.

13. Berasain C and Ávila MA: LKB1: Controlling Quiescence and Genomic Integrity at Home. Trends Endocrinol Metab: April 5, 2018 (Epub ahead of print).

14. Fabian MR, Sonenberg N and Filipowicz W: Regulation of mRNA translation and stability by microRNAs. Annu Rev Biochem 79: 351-379, 2010.

15. Carretero J, Shimamura T, Rikova K, Jackson AL, Wilkerson MD, Borgman CL, Buttarazzi MS, Sanofsky BA, McNamara KL, Brandstetter KA, et al: Integrative genomic and proteomic analyses identify targets for Lkb1-deficient metastatic lung tumors. Cancer Cell 17: 547-559, 2010.

16. Zhang W, Gao Y, Li F, Tong X, Ren Y, Han X, Yao S, Long F, Yang $\mathrm{Z}$, Fan $\mathrm{H}$, et al: YAP promotes malignant progression of Lkb1-deficient lung adenocarcinoma through downstream regulation of survivin. Cancer Res 75: 4450-4457, 2015.

17. Calles A, Sholl LM, Rodig SJ, Pelton AK, Hornick JL, Butaney M, Lydon C, Dahlberg SE, Oxnard GR, Jackman DM, et al: Immunohistochemical loss of LKB1 is a biomarker for more aggressive biology in KRAS-mutant lung adenocarcinoma. Clin Cancer Res 21: 2851-2860, 2015 .
18. Travis WD, Brambilla E, Noguchi M, Nicholson AG, Geisinger KR, Yatabe Y, Beer DG, Powell CA, Riely GJ, Van Schil PE, et al: International association for the study of lung cancer/american thoracic society/european respiratory society international multidisciplinary classification of lung adenocarcinoma. J Thorac Oncol 6: 244-285, 2011.

19. Travis WD, Brambilla E, Noguchi M, Nicholson AG, Geisinger K, Yatabe Y, Ishikawa Y, Wistuba I, Flieder DB, Franklin W, et al: Diagnosis of lung cancer in small biopsies and cytology: Implications of the 2011 International Association for the Study of Lung Cancer/American Thoracic Society/European Respiratory Society classification. Arch Pathol Lab Med 137: 668-684, 2013

20. Zhang J, Qin L, Han L, Zhao Y, Jing H, Song W and Shi H: Role of MicroRNA-93 in pathogenesis of left ventricular remodelling via targeting cyclin-D1. Med Sci Monit 23: 3981-3988, 2017.

21. Tang Q, Zou Z, Zou C, Zhang Q, Huang R, Guan X, Li Q, Han Z, Wang D, Wei H, et al: MicroRNA-93 suppress colorectal cancer development via Wnt/ $\beta$-catenin pathway downregulating. Tumour Biol 36: 1701-1710, 2015.

22. Avtanski DB, Nagalingam A, Bonner MY, Arbiser JL, Saxena NK and Sharma D: Honokiol activates LKB1-miR-34a axis and antagonizes the oncogenic actions of leptin in breast cancer. Oncotarget 6: 29947-29962, 2015.

23. Zhu XB, Zhang ZC, Han GS, Han JZ and Qiu DP: Overexpression of miR 214 promotes the progression of human osteosarcoma by regulating the Wnt $/ \beta$ catenin signaling pathway. Mol Med Rep 15: 1884-1892,2017.

24. Kang J, Kim W, Lee S, Kwon D, Chun J, Son B, Kim E, Lee JM, Youn $\mathrm{H}$ and Youn B: TFAP2C promotes lung tumorigenesis and aggressiveness through miR-183- and miR-33a-mediated cell cycle regulation. Oncogene 36: 1585-1596, 2017.

25. Yabushita S, Fukamachi K, Tanaka H, Sumida K, Deguchi Y, Sukata T, Kawamura S, Uwagawa S, Suzui M and Tsuda H: Circulating microRNAs in serum of human K-ras oncogene transgenic rats with pancreatic ductal adenocarcinomas. Pancreas 41: 1013-1018, 2012.

26. Wang D, Lu G, Shao Y and Xu D: miR-182 promotes prostate cancer progression through activating Wnt/ $\beta$-catenin signal pathway. Biomed Pharmacother 99: 334-339, 2018

27. Beezhold K, Klei LR and Barchowsky A: Regulation of cyclin D1 by arsenic and microRNA inhibits adipogenesis. Toxicol Lett 265: 147-155, 2017

28. Wu Z, He B, He J and Mao X: Upregulation of miR-153 promotes cell proliferation via downregulation of the PTEN tumor suppressor gene in human prostate cancer. Prostate 73: 596-604, 2013.

29. Liu X, Lv XB, Wang XP, Sang Y, Xu S, Hu K, Wu M, Liang Y, Liu P, Tang J, et al: MiR-138 suppressed nasopharyngeal carcinoma growth and tumorigenesis by targeting the CCND1 oncogene. Cell Cycle 11: 2495-2506, 2012.

30. Waggott D, Chu K, Yin S, Wouters BG, Liu FF and Boutros PC: NanoStringNorm: An extensible R package for the pre-processing of NanoString mRNA and miRNA data. Bioinformatics 28 : 1546-1548, 2012

31. Tian DL, Liu HX, Zhang L, Yin HN, Hu YX, Zhao HR, Chen DY, Han LB, Li Y and Li HW: Surgery for young patients with lung cancer. Lung Cancer 42: 215-220, 2003.

32. Liu NS, Spitz MR, Kemp BL, Cooksley C, Fossella FV, Lee JS, Hong WK and Khuri FR: Adenocarcinoma of the lung in young patients: The M. D. Anderson experience. Cancer 88: 1837-1841, 2000.

33. Kuo CW, Chen YM, Chao JY, Tsai CM and Perng RP: Non-small cell lung cancer in very young and very old patients. Chest 117: 354-357, 2000

34. Skarin AT, Herbst RS, Leong TL, Bailey A and Sugarbaker D: Lung cancer in patients under age 40. Lung Cancer 32: 255-264, 2001.

35. Blanco M, García-Fontán E, Rivo JE, Repáaz JR, Obeso GA and Cañizares MA: Bronchogenic carcinoma in patients under 50 years old. Clin Transl Oncol 11: 322-325, 2009.

36. Weiss $J$ and Langer C: Treatment of lung cancer in the elderly patient. Semin Respir Crit Care Med 34: 802-809, 2013.

37. Davidoff AJ, Tang M, Seal B and Edelman MJ: Chemotherapy and survival benefit in elderly patients with advanced non-small-cell lung cancer. J Clin Oncol 28: 2191-2197, 2010.

38. Beckett P, Callister M, Tata LJ, Harrison R, Peake MD, Stanley R, Woolhouse I, Slade M and Hubbard RB: Clinical management of older people with non-small cell lung cancer in England. Thorax 67: 836-839, 2012 
39. Meoni G, Cecere FL, Lucherini E and Di Costanzo F: Medical treatment of advanced non-small cell lung cancer in elderly patients: A review of the role of chemotherapy and targeted agents. J Geriatr Oncol 4: 282-290, 2013.

40. Ye T, Pan Y, Wang R, Hu H, Zhang Y, Li H, Wang L, Sun Y and Chen $\mathrm{H}$ : Analysis of the molecular and clinicopathologic features of surgically resected lung adenocarcinoma in patients under 40 years old. J Thorac Dis 6: 1396-1402, 2014.

41. Kim L, Kim KH, Yoon YH, Ryu JS, Choi SJ, Park IS, Han JY, Kim JM and Chu YC: Clinicopathologic and molecular characteristics of lung adenocarcinoma arising in young patients. J Korean Med Sci 27: 1027-1036, 2012.

42. Pan Y, Zhang Y, Li Y, Hu H, Wang L, Li H, Wang R, Ye T, Luo X, Zhang Y, et al: ALK, ROS1 and RET fusions in 1139 lung adenocarcinomas: A comprehensive study of common and fusion pattern-specific clinicopathologic, histologic and cytologic features. Lung Cancer 84: 121-126, 2014.

43. Radzikowska E, Roszkowski K and Głaz P: Lung cancer in patients under 50 years old. Lung Cancer 33: 203-211, 2001.

44. Sekine I, Nishiwaki Y, Yokose T, Nagai K, Suzuki K and Kodama T: Young lung cancer patients in Japan: Different characteristics between the sexes. Ann Thorac Surg 67: 1451-1455, 1999.

45. Shackelford DB, Abt E, Gerken L, Vasquez DS, Seki A Leblanc M, Wei L, Fishbein MC, Czernin J, Mischel PS, et al: LKB1 inactivation dictates therapeutic response of non-small cell lung cancer to the metabolism drug phenformin. Cancer Cell 23: 143-158, 2013.

46. Inge LJ, Coon KD, Smith MA and Bremner RM: Expression of LKB1 tumor suppressor in non-small cell lung cancer determines sensitivity to 2-deoxyglucose. J Thorac Cardiovasc Surg 137: 580-586, 2009

47. Carretero J, Medina PP, Blanco R, Smit L, Tang M, Roncador G, Maestre L, Conde E, Lopez-Rios F, Clevers HC, et al: Dysfunctional AMPK activity, signalling through mTOR and survival in response to energetic stress in LKB1-deficient lung cancer. Oncogene 26: 1616-1625, 2007.

48. Mahoney CL, Choudhury B, Davies H, Edkins S, Greenman C, Haaften G, Mironenko T, Santarius T, Stevens C, Stratton MR, et al: LKB1/KRAS mutant lung cancers constitute a genetic subset of NSCLC with increased sensitivity to MAPK and mTOR signalling inhibition. Br J Cancer 100: 370-375, 2009.

49. Whang YM, Park SI, Trenary IA, Egnatchik RA, Fessel JP, Kaufman JM, Carbone DP and Young JD: LKB1 deficiency enhances sensitivity to energetic stress induced by erlotinib treatment in non-small-cell lung cancer (NSCLC) cells. Oncogene 35: 856-866, 2016.

50. Jian SF, Hsiao CC, Chen SY, Weng CC, Kuo TL, Wu DC, Hung WC and Cheng KH: Utilization of liquid chromatography mass spectrometry analyses to identify LKB1-APC interaction in modulating Wnt $/ \beta$-catenin pathway of lung cancer cells. Mol Cancer Res 12: 622-635, 2014.

51. Geiss GK, Bumgarner RE, Birditt B, Dahl T, Dowidar N, Dunaway DL, Fell HP, Ferree S, George RD, Grogan T, et al Direct multiplexed measurement of gene expression with color-coded probe pairs. Nat Biotechnol 26: 317-325, 2008.

52. Reis PP, Waldron L, Goswami RS, Xu W, Xuan Y Perez-Ordonez B, Gullane P, Irish J, Jurisica I and Kamel-Reid S: mRNA transcript quantification in archival samples using multiplexed, color-coded probes. BMC Biotechnol 11: 46, 2011.
53. Mairinger FD, Walter RF, Werner R, Christoph DC, Ting S, Vollbrecht C, Zarogoulidis K, Huang H, Li Q, Schmid KW, et al: Activation of angiogenesis differs strongly between pulmonary carcinoids and neuroendocrine carinomas and is crucial for carcinoid tumourgenesis. J Cancer 5: 465-471, 2014.

54. Veldman-Jones MH, Brant R, Rooney C, Geh C, Emery H, Harbron CG, Wappett M, Sharpe A, Dymond M, Barrett JC, et al: Evaluating robustness and sensitivity of the NanoString Technologies nCounter platform to enable multiplexed gene expression analysis of clinical samples. Cancer Res 75: 2587-2593, 2015

55. Walter RF, Mairinger FD, Wohlschlaeger J, Worm K, Ting S, Vollbrecht C, Schmid KW and Hager T: FFPE tissue as a feasible source for gene expression analysis - a comparison of three reference genes and one tumor marker. Pathol Res Pract 209: 784-789, 2013.

56. Chen L, Engel BE, Welsh EA, Yoder SJ, Brantley SG, Chen DT, Beg AA, Cao C, Kaye FJ, Haura EB, et al: A Sensitive NanoString-Based Assay to Score STK11 (LKB1) Pathway Disruption in Lung Adenocarcinoma. J Thorac Oncol 11: 838-849, 2016

57. Ujiie H, Kadota K, Chaft JE, Buitrago D, Sima CS, Lee MC, Huang J, Travis WD, Rizk NP, Rudin CM, et al: Solid Predominant Histologic Subtype in Resected Stage I Lung Adenocarcinoma Is an Independent Predictor of Early, Extrathoracic, Multisite Recurrence and of Poor Postrecurrence Survival. J Clin Oncol 33 : 2877-2884, 2015.

58. Du L, Zhao Z, Ma X, Hsiao TH, Chen Y, Young E, Suraokar M, Wistuba I, Minna JD and Pertsemlidis A: miR-93-directed downregulation of DAB2 defines a novel oncogenic pathway in lung cancer. Oncogene 33: 4307-4315, 2014.

59. Xiao J, Zou Y, Chen X, Gao Y, Xie M, Lu X, Li W, He B, He S, You S, et al: The Prognostic Value of Decreased LKB1 in Solid Tumors: A Meta-Analysis. PLoS One 11: e0152674, 2016.

60. Xu P, Zhao M, Liu Z, Liu Y, Chen Y, Luo R and Fang W: Elevated nuclear CCND1 expression confers an unfavorable prognosis for early stage lung adenocarcinoma patients. Int J Clin Exp Pathol 8: 15887-15894, 2015.

61. Deep G and Agarwal R: Targeting tumor microenvironment with silibinin: Promise and potential for a translational cancer chemopreventive strategy. Curr Cancer Drug Targets 13: 486-499, 2013.

62. Gao Y, Xiao Q, Ma H, Li L, Liu J, Feng Y, Fang Z, Wu J, Han X, Zhang J, et al: LKB1 inhibits lung cancer progression through lysyl oxidase and extracellular matrix remodeling. Proc Natl Acad Sci USA 107: 18892-18897, 2010.

63. Hou X, Du H, Quan X, Shi L, Zhang Q, Wu Y, Liu Y, Xiao J, Li Y, Lu L, et al: Silibinin Inhibits NSCLC Metastasis by targeting the EGFR/LOX pathway. Front Pharmacol 9: 21, 2018.

64. Zhong K, Chen K, Han L and Li B: MicroRNA-30b/c inhibits non-small cell lung cancer cell proliferation by targeting Rab18. BMC Cancer 14: 703, 2014.

65. de la Cueva A, Emmerling M, Lim SL, Yang S, Trackman PC, Sonenshein GE and Kirsch KH: A polymorphism in the lysyl oxidase propeptide domain accelerates carcinogen-induced cancer. Carcinogenesis: March 22, 2018 (Epub ahead of print).

This work is licensed under a Creative Common Attribution-NonCommercial-NoDerivatives 4.0 International (CC BY-NC-ND 4.0) License. 